\title{
Risk factors associated with canine overweightness and obesity in an owner-reported survey
}

\section{LeeAnn Perry}

NomNomNow https://orcid.org/0000-0002-0039-2222

Justin William Shmalberg

NomNomNow, Inc.

Jirayu Tanprasertsuk

NomNomNow, Inc.

\section{Dan Massey}

NomNomNow, Inc.

Ryan William Honaker

NomNomNow, Inc.

Aashish R Jha ( $\nabla$ aashish@nomnomnow.com )

https://orcid.org/0000-0003-3227-1086

\section{Research article}

Keywords: Canine, dog, overweight, obesity, diet, dry food, probiotics, treats, fresh food, machine learning

Posted Date: March 16th, 2020

DOI: https://doi.org/10.21203/rs.2.20774/v2

License: (c) (i) This work is licensed under a Creative Commons Attribution 4.0 International License.

Read Full License 


\section{Abstract}

Background Overweightness and obesity in dogs are associated with negative health outcomes. A better understanding of risk factors associated with canine weight is fundamental to identifying preventative interventions and treatments. In this cross-sectional study, we used a direct to consumer approach to collect body condition scores (BCS), as well as demographic, diet, and lifestyle data on 4,446 dogs. BCS was assessed by owners using a 9-point system and categorized as ideal (BCS 4-5), overweight (BCS 6), and obese (BCS 7+). Following univariate analyses, a stepwise procedure was used to select variables which were included in multivariate logistic regression models. One model was created to compare ideal to all overweight and obese dogs, and another was created to compare ideal to obese dogs only. We then used Elastic Net selection and XGBoost variable importance measures to validate these results. Results Overall, 1,480 (33\%) of dogs were reported to be overweight or obese, of which 356 ( $8 \%$ total) of dogs were reported to be obese. Seven factors were significantly associated with both overweightness/obesity and obesity alone in all three analyses (stepwise, Elastic Net, and XGBoost): diet composition, probiotic supplementation, treat quantity, exercise, age, food motivation level, and pet appetite. Neutering was also associated with overweightness/obesity in all analyses. Conclusions This study recapitulated established risk factors associated with BCS (age, exercise, neutering). Moreover, we elucidated associations between previously examined risk factors and BCS (diet composition, treat consumption, and temperament) and identified a novel factor (probiotic supplementation). Specifically, relative to dogs on fresh food diets, BCS was higher in dogs eating dry food both alone and in combination with other foods. Furthermore, dogs receiving probiotics, but not other forms of supplementation, were more likely to have an ideal BCS. Future studies should corroborate these findings with experimental manipulations.

\section{Background}

Overweightness and obesity are major health concerns in both humans and companion dogs. Weight issues have been associated with myriad negative health conditions as well as decreased life span $(1,2)$. In the largest study to date, the prevalence of veterinarian-assessed overweightness and obesity of dogs in the United States has been reported to be $34 \%$ and $5 \%$ respectively (3). Globally, canine overweightness has been determined to range from $6-31 \%$ in European countries, $44 \%$ in China, $40 \%$ in Japan, and $26 \%$ in Australia (4-7).

Clinical assessment of overweightness and obesity relies on body condition scores (BCS) based on visual inspection and palpation. A number of studies have identified risk factors associated with increased BCS, including increased age $(3-6,8,9)$, neutering $(3,5,6,9,10)$, and decreased exercise $(11,12)$. Some studies have also identified an effect of different feeding practices. Home-made diets, table foods, semi-moist foods, and canned foods have all been associated with overweightness and obesity $(3,12)$. The consumption of treats and snacks has also been identified as a risk factor $(8,10,11)$. Despite these findings, many of these studies have been limited by comparatively smaller sample sizes (8), or have included only a handful of risk factors (6). Thus, investigating factors associated with canine body weight using a larger cohort and a more comprehensive list of risk factors is warranted. 
This study addresses these drawbacks by engaging a direct-to-consumer data collection model wherein a large pool of pet owners distributed widely across the United States completed an extensive online health assessment. The volume of data collected not only allowed us to use standard analytic methods, but also permitted the use of machine learning approaches that do not have the same biases or assumptions of traditional statistical methods. Our results recapitulate findings from previous studies on canine overweightness and obesity, provide additional evidence for factors with conflicting results in the literature, and identify novel factors associated with overweightness and obesity.

\section{Results}

Out of a total of 4,446 dogs, 2,967 (67\%) were at an ideal weight, defined as an owner-reported body condition score of 4-5 on a previously-validated 9-point system (BCS 4-5; (13)) and 1,480 (33\%) were overweight or obese (BCS $\geq 6$ ). Of these dogs with higher $B C S, 1,124$ ( $25 \%$ of total) were overweight (BCS 6) and 356 ( $8 \%$ of total) were obese (BCS $\geq 7)$. In terms of sex, 1,727 (39\%) were neutered male, 1,733 (39\%) were neutered female, 262 (5.9\%) were intact male, and 197 (4.4\%) were intact female; 527 did not include both sex and neutered status. The average age was $6.74 \pm 4.09$ years and the average weight was $13.6 \pm 11.8 \mathrm{~kg}$.

\section{Identification of Risk Factors Associated with Overweightness and Obesity}

Significant Risk Factors Identified via Univariate Analysis:

To identify factors associated with increased BCS, we performed two univariate analyses comparing ideal weight dogs $(N=2,966)$ to overweight/obese dogs $(N=1,480)$ as well as to obese dogs only $(N=356)$. Of the 45 variables selected as outlined in Methods, 22 (49\%) were significantly associated with overweightness/obesity in a univariate analysis $(\mathrm{p}<0.05, \mathrm{~N}=4,446)$ and $18(40 \%)$ were significantly associated with obesity $(\mathrm{p}<0.05, \mathrm{~N}=3,322)$. The relationships between these variables and BCS are summarized in Table 1 [See end of document]. The 18 variables positively associated with both overweightness/obesity and obesity were diet combinations containing dry food, increased treat quantity, lack of probiotic consumption, increased age, decreased exercise per week, neutering, increased pet appetite, increased food motivation, lower overall mood, decreased conspecific interaction, increased tail chasing, decreased prey drive, presence of other dogs in the household, rural home environment, conventional-only medicine type, household tobacco use, food intolerances, and rescue or other acquisition method. Four additional variables positively associated with BCS in the overweightness/obesity analysis were the use of dental chews, sharing or cooking food, increased overall nervousness, and decreased dental visit frequency.

\section{Significant Risk Factors Identified via Stepwise Multivariable Analysis:}

Since body weight is a complex trait that can be influenced by multiple variables, we performed multivariate analysis to understand how different variables are associated with BCS when they are taken together. We performed these analyses in the overweight/obese and obese groups separately. The results 
from the two stepwise logistic regression models comparing ideal weight dogs $(N=2,725)$ to overweight/obese dogs $(\mathrm{N}=1,384)$ as well as obese dogs $(\mathrm{N}=327)$ are presented in Table 2 [See end of document]. Due to missing data in the selected variables, 337 dogs from the total dataset were dropped from this logistic regression. Log odds for significant variables are presented in Figure 1. The variables significantly associated with overweightness/obesity were age, exercise per week, food motivation level, overall mood, pet appetite, sharing food, neutering, treat quantity, probiotic supplements, home environment, diet, and dental treatment frequency $(p<0.05$, stepwise logistic regression, $N=4,109)$. The variables significantly associated with obesity alone were age, exercise per week, food motivation level, other dogs in the household, overall mood, pet appetite, neutering, tail chasing frequency, treat quantity, probiotic supplements, medicine type, diet, and dental treatment frequency $(p<0.05$, stepwise logistic regression, $\mathrm{N}=3,052)$. The intersection of variables in the two models were age, exercise per week, food motivation level, overall mood, pet appetite, neutering, treat quantity, probiotic supplements, diet, and dental treatment frequency.

Given the nonlinear relationship between age and body condition reported by others $(3,5,6,9)$, age was entered as both a linear and quadratic term in the logistic regression model. In the context of the model, both the linear and quadratic terms had odds ratios that were statistically significant $(p<0.0001)$. The inclusion of the quadratic term significantly improved both the overweight/obese and obese only logistic regression models, as determined by nested model ANOVA $(p<0.0001$, likelihood ratio test).

\section{Significant Risk Factors Selected via Elastic Net Analysis:}

Collinearity poses a major issue for stepwise models, since only a subset of a group of collinear variables may be selected, such that the final ensemble of variables may be influenced by noise. Elastic Net is a method that combines the $L_{1}$ and $L_{2}$ penalties used in the Lasso and ridge methods, respectively. It addresses the collinearity issue, as it exhibits a grouping effect (14) wherein coefficients of correlated variables tend to be similar. Thus, through the Elastic Net algorithm we may see if any important variables are being masked by their correlations with others.

For both the overweight/obese and obese only models, the most significant ensemble of risk factors was selected as detailed in Methods. Factors that appeared in both the optimal model for overweightness/obesity and the optimal model for obesity alone were: pet appetite, treat quantity, exercise, probiotic supplementation, diet, mood, food motivation level, and age. The overweightness/obesity model also included neutering, home environment, and sharing food, while the obesity model also included medicine type. With the exception of medicine type, all of these variables are within the subset of those selected by stepwise logistic regression. Variables selected by the Elastic Net are presented in [Additional File 1] and [Additional File 2]. Comparisons between variables selected by Elastic Net and other methods are presented in Table 3 [See end of document].

Significant Risk Factors Selected via XGBoost Analysis: 
Another issue with the stepwise model is that non-linear effects are not accounted for. We addressed this by using XGBoost, a tree-based machine learning algorithm (15). A tree-based model can establish decision points at multiple different values, and thus the final variable importance in the model encompasses non-linear relationships including interactions between variables. Through XGBoost we may identify which variables, if any, we should examine in terms of higher-order interactions or polynomial models. Factors that appeared in both the optimal model for overweightness/obesity and the optimal model for obesity were: age, pet appetite, exercise, treat quantity, food motivation level, diet, and probiotic consumption. The overweightness/obesity model also included neutering. Each one of these variables was also selected by stepwise logistic regression and Elastic Net. The variable importance plots from the XGBoost models are presented in [Additional File 3] and [Additional File 4]. Comparisons between variables selected by XGBoost and other methods are presented in Table 3 [see end of document].

\section{Healthy Subgroup:}

We repeated the multivariate logistic regression analysis with only the subgroup of dogs that were reported to have no major health conditions, in order to remove the possibly confounding effects of disease and treatment variables. This subset consisted of dogs that did not have pancreatitis, diabetes, kidney issues, liver disease, heart issues, cancer, or gastrointestinal conditions ( $N=3,173,71 \%$ of total dataset). Of these dogs, 2,118 (67\%) were at an ideal weight (BCS 4-5) and 1,055 (33\%) were either overweight/obese $(\mathrm{BCS} \geq 6)$ or obese (BCS $\geq 7)$; these were further categorized into 792 ( $25 \%$ of total) that were overweight and 263 ( $8 \%$ of total) that were obese. These proportions were not statistically significantly different from the proportions in the overall sample $\left(p<0.05, \chi^{2}\right.$ test). Thirteen of the 15 variables selected from the total dataset remained significant despite decreased power to detect significant effects. These findings are available in Table 4 [See end of document]. Due to missingness in the selected variables, 192 dogs were dropped from the healthy subgroup logistic regression.

\section{Individual Contributions of Selected Risk Factors}

Among the 7 risk factors identified by all of the eight selection methods (univariate, stepwise, Elastic Net, and XGBoost each undertaken for both overweightness/obesity and obesity alone) as presented in Table 3 [see end of document] were diet, age, exercise, probiotic supplementation, and treat quantity. We further examined the individual contributions of these five risk factors to BCS.

\section{Diet:}

We examined the relationship between the most common diet types and both overweightness/obesity (Figure 2) and obesity alone (Figure 3). Since a fresh food only diet was the largest category (besides "Other", see Methods) we used this as our reference level in the logistic regression.

Relative to dogs on a fresh food only diet, dogs fed dry plus canned food (OR=1.85, $p<0.0001)$, dry food only $(O R=1.45, p<0.0001)$, and dry plus fresh food $(O R=1.3, p=0.03)$ were more likely to be 
overweight/obese. Dry plus canned food $(\mathrm{OR}=2.6, \mathrm{p}<0.0001)$ and dry food only $(\mathrm{OR}=2.1, \mathrm{p}<0.0001)$ were also risk factors for being obese, but not dry plus fresh food ( $p>0.05)$. Dogs fed raw food only were less likely to be overweight/obese $(O R=0.5, p=0.005)$, but there was no effect on obesity alone $(p>0.05)$.

\section{Age:}

Given the strong relationship between body condition and age in both the univariate and multivariate models, we investigated this in further detail. We found that likelihood of overweightness peaked around age 8-10, decreasing with further aging (Figure 4, A). Likelihood of obesity alone showed a similar nonlinear pattern. This relationship supports our use of higher-order polynomial age terms in the logistic regression models.

\section{Exercise:}

Since exercise was shown to be statistically significant in both the univariate and multivariate models $(p<0.0001$ ), we further considered this relationship (Figure 4, B). We found that incrementally increasing the amount of exercise per week decreased the likelihood of overweightness/obesity. The same pattern holds for obesity.

\section{Probiotics:}

We also examined the relationship between probiotic supplementation and BCS (Figure 4, C). In total, 844 dogs were currently taking probiotics, and respondents reported using a broad range of commercial formulations. We found that probiotic supplementation was significant both with respect to overweight/obese status $(O R=0.65, p<0.0001)$ and obese status $(O R=0.46, p<0.0001)$ with dogs taking probiotics being more likely to be at an ideal weight.

Given that dogs receiving probiotics may be more likely to be at a lower weight due to having a medical condition, we repeated this analysis using only the healthy cohort as previously defined $(N=3,173)$. We found a significant relationship with both overweight/obese status $(O R=0.65, p<0.0001)$ and obese status $(\mathrm{OR}=0.52, \mathrm{p}=0.002)$ in this cohort as well.

Since supplement usage may indicate increased owner health consciousness, we also performed a similar test with the other supplements included in our analysis in order to determine if this significant effect was specific to probiotics. We examined prebiotics ( $N=183)$, multivitamins ( $N=425), C B D$ oil $(\mathrm{N}=540)$, fish oil $(\mathrm{N}=812)$, herbal supplements $(\mathrm{N}=207)$, and immune support $(\mathrm{N}=121)$. None of these supplements showed a significant relationship with either overweight/obese status or obese status in chisquare tests $(p>0.05)$.

\section{Treats:}


Finally, we examined the univariate association between treat intake quantity (by percentage of caloric needs being met by treats) and BCS (Figure 4, D). Both the univariate and multivariate analyses confirmed that, while giving over $10 \%$ of a dog's diet in treats was associated with higher BCS, there was no significant difference between giving under $10 \%$ of a dog's diet in treats and abstaining completely, suggesting that giving treats in moderation is not a risk factor for either overweightness or obesity.

\section{Non-Significant Factors:}

Given that some respondents ( $\mathrm{N}=593)$ gave data for multiple dogs, and that joint households may exhibit shared environmental factors not captured by existent survey questions, we determined if there was a significant effect of household on reported body condition. We entered household into the logistic regression model as a random effect, and an analysis of deviance showed that it was not significant $(p>0.05)$. Furthermore, given findings from other studies that identified a relationship between sex and BCS (e.g. (6), or a significant interaction between sex and neutered status on BCS (10), the analysis was repeated in the subset of animals for which sex data were provided $(\mathrm{N}=3,922)$ but sex was not significant either as a main effect or in interaction with neutering ( $p>0.05)$. Given previously reported overweightness rates of $52 \%$ and $41 \%$ for females and males respectively (5), and $\alpha=0.05$, we had $\beta>.99$ power to detect a main effect, and following previously published guidelines for calculating power for interactions (16), we calculated that we had $\beta>.90$ power to detect an interaction between sex and neutering. Therefore, we are relatively confident in reporting that no relationship between sex and BCS exists in this sample.

\section{Discussion}

This study employed a cross-sectional direct-to-consumer data collection approach to identify risk factors associated with increased owner-assessed body condition. Overweightness and obesity were common issues in this population, with $33 \%$ of dogs reported as overweight/obese and $8 \%$ reported as obese. This is comparable to the respective figures obtained in a study of 21,754 dogs in the United States wherein body condition scores were assessed by a veterinarian (3). The large dataset assembled here allowed us to identify and then validate risk factors using multiple approaches. Overweightness/obesity and obesity were each examined through three logistic regression models, with variables chosen through stepwise selection, Elastic Net selection, and an XGBoost machine learning model.

Many of the risk factors identified recapitulate robust findings from previous studies. Exercise has previously been identified as protective against obesity $(11,12,17)$. Neutering has also been found to be a risk factor for overweightness but not obesity (6), and we find more significant relationships with the combined overweightness/obesity models than with the models for obesity alone. Though this result may be due to decreased power, this potential distinction in severity may be important for dog owners to recognize when weighing the potential outcomes of neutering. This relationship is corroborated by studies showing that neutering dogs results in lower daily energy requirements combined with higher food consumption (18). Sex has previously been found to be a risk factor both alone (6) and in interaction with neutering (10), though other studies did not identify a significant effect (9). We 
specifically tested for an association between sex and weight and, despite having adequate power, did not detect an effect in our sample. While a number of studies $(4,5,8)$ have reported increased age as a risk factor for weight issues, we found in our sample that weight peaks around age 8-10 years, with older animals less likely to be overweight or obese than their middle-aged counterparts. This mirrors findings from other larger studies $(3,5,6,9)$. This finding may reflect the decreased lifespans of overweight and obese dogs.

One novel finding of our study is the association between increased BCS and the consumption of dry food, which has previously been observed in cats $(19,20)$ but not in dogs $(3,11)$. Specifically, we found that, compared to fresh food, dry food is significantly associated with overweightness/obesity, both alone and in combination with canned or fresh food. Furthermore, dry food only diets and dry plus canned combination diets were significantly associated with obesity, but not dry plus fresh combination diets. This may indicate that supplementing with other types of food ameliorates the more obesogenic consequences of certain diets. The relationship between dry food and increased BCS may be partially due to the tendency of owners to inaccurately measure dry food portions (21), which may be alleviated by the decreased caloric density of fresh and raw foods. We posit that previous studies did not identify a relationship between dry food and increased body weight due to the lack of fresh and raw alternatives commercially available in past years. We also found that feeding commercial and home-prepared fresh, frozen, and raw foods is associated with a lower likelihood of being overweight or obese; however, diets containing raw animal products may contain higher rates of bacterial contamination than other foods and may pose health risks to companion animals (22). Observed differences in dietary factors could be due to a number of non-nutritional factors such as the provided portion sizes, the individualized portioning of some fresh diets, or the higher price point per calorie of some diets. Future studies should examine the effects of varied proportions of these dietary elements and experimental dietary manipulation to determine the direction of causality.

Another novel finding is that supplementation with probiotics is associated with being at an ideal weight. This finding is specific to probiotics among other supplements reported in the survey, and the effect persists in a sample composed of dogs without major reported health issues. This relationship is supported by work that shows significant differences in the gut microbiota of normal and obese dogs (23), as well as recent reviews and meta-analyses of experimental and clinical trials of probiotic supplementation in different species (24-26). However, to the best of our knowledge this is the first large cross-sectional demographic study that has specifically identified probiotic supplementation as a potential protective factor with regard to overweightness and obesity. The mechanisms behind this relationship are unclear, but in addition to modulating energy harvest and nutrient absorption through alterations in microbiota, probiotics might act through improving insulin sensitivity (27) or increasing satiety (24). Additional prospective data should be collected to identify whether there is a causal relationship.

We also identified treat feeding practices as robust predictors of body condition. In contrast to previous studies which identify even a moderate frequency of treat-feeding as a risk factor (8) we find that feeding 
treats in moderation, i.e. with $10 \%$ or less of total caloric needs being met by treats, is neither associated with overweightness/obesity nor obesity. This discordance between findings may be due to differential effects of treat quantity and treat frequency. However, these results should be interpreted cautiously as owner assessment of calories provided by a given treat may often be imprecise.

The presence of other dogs has been previously studied as a risk factor for increased BCS, with some studies identifying living in a single-dog household as a risk factor (11) and others finding no significant relationship (5). We find that the presence of other dogs in the household is associated with higher body weight, and we posit this may be due to the difficulty of implementing food restriction in the presence of a dog of healthy weight that is being concurrently fed.

Our models also included owner assessments of canine temperamental factors, including food motivation level, pet appetite, and overall mood. Significant relationships between obesity and temperamental factors such as appetite and food motivation have previously been identified $(12,28,29)$. It is possible that dogs that express higher food motivation and appetite receive more calories from their owners, and food-seeking behavior may be associated with decreased owner compliance with weight loss regimens. While dogs' subjective experience is difficult to measure, owner-perceived emotional eating in dogs has been associated with owner-assessed overall mood and anxiety (30). Tail-chasing, which emerged as a significant factor in some models, may also be an index of behavioral issues (31). While the links between behavior, mood, and obesity are unclear and likely to be multifactorial, serotonin has been implicated in both mood and satiety (32) and serotonin-reuptake inhibitors have been shown to decrease tail-chasing behavior (33).

Finally, we also note that our models identified additional variables, though it is difficult to pinpoint the statistical reasons for these differences. We identified increased dental treatment frequency as significant; however, the interpretation of this finding remains unclear. It is possible that increased dental visit frequency reflects higher health consciousness in owners or more frequent veterinary counseling on prevention of weight issues. A causal relationship between periodontal inflammation and obesity seems unlikely, but there could be effects on the microbiome or other processes that might contribute to adiposity. Some of our models also identified a significant association between rural environments and increased BCS, which is corroborated by previous studies $(6,9)$.

Limitations of this investigation include the use of owner assessment of BCS and owner report of other questionnaire items; prior studies have shown that owners inaccurately report body condition (34). However, we validated the use of BCS in this sample by cross-referencing BCS against owner-reported current-to-ideal body weight ratios and identified significant overlap as detailed in Methods. Another shortcoming is that we did not solicit demographic or lifestyle data of the owners, such as age and income, which have been previously shown to be associated with canine weight issues (8). Another potential limitation of our findings is selection bias, as our data were drawn primarily from the customer base of a pet health company providing individually portioned fresh meals, which may be more healthconscious than the aggregate dog owning population. However, this study is the first to report results 
from this unique population, broadly in accord with previously reported risk factors, supporting the generalizability of these findings. Finally, as the associations between the reported risk factors and BCS were cross-sectional, temporality and causality were not addressed. Future studies should seek to experimentally manipulate these risk factors individually or in combination to observe their potentially synergistic effects on weight loss or maintenance, particularly diet, probiotics, and treat quantity as they may be most easily manipulated by dog owners.

\section{Conclusions}

In this cross-sectional, owner-reported study of 4,446 dogs, we identified risk factors for overweightness and obesity using stepwise selection, and then confirmed these findings using Elastic Net and XGBoost. Our findings recapitulated risk factors robustly identified by other studies, including exercise, neutering, and a non-linear contribution of age. We also further elucidated the contribution of previously studied risk factors; we identified dry food consumption, excessive treat intake, and canine temperament as risk factors. Finally, we identified probiotic supplementation as a potential protective factor. These findings are of clinical and practical significance because the demographic factors identified may be used to proactively identify dogs at increased risk for overweightness and obesity, and the lifestyle factors identified may guide the development of interventions. Further studies employing experimental manipulations are needed to establish whether these relationships are causal.

\section{Methods}

\section{Data collection and selection procedures}

Customers of NomNomNow, a pet food and health company, were asked to complete a comprehensive online health assessment for each pet in their care, composed of five broadly targeted questionnaires containing questions about signalment, overall wellness, diet and lifestyle, medical history, and product preferences. These included single-choice checkbox, multiple-choice radio-button, dropdown, and fill-inthe-blank questions. We collected survey responses from a total of 7,942 dogs of which 5,135 were complete. Dogs under one year of age $(\mathrm{N}=415)$, pregnant or lactating dogs $(\mathrm{N}=4)$, and underweight dogs $(\mathrm{N}=272)$ were excluded from the analysis, yielding a final sample of 4,446 dogs from 3,853 unique households broadly distributed across the United States. A maximum of 122 questions were asked regarding each dog, as some questions were served contingent upon responses to other questions. After dummy-coding and grouping, there were 372 individual features, which were reduced to 47 after removing variables related to medical conditions and treatment, product preferences, and highly correlated or redundant questions. This initial exclusion step was performed because Monte Carlo simulations show improved performance in stepwise models with fewer nuisance variables (35). After further removing variables that were more than $5 \%$ incomplete, we were left with 45 features which were used for subsequent analysis. The survey questions that contributed to the final features are detailed in [Additional File 5]. 
Weight status was assessed by dog owners using an image-based body condition score (BCS) chart accompanied by a verbal description. BCS has been shown to be strongly correlated with gold-standard dual-energy X-ray absorptiometry (DEXA) scans (36) and is regularly used both by veterinarians and researchers for clinical assessment of overweightness and obesity. Respondents were shown six options reflecting a nine point scale (BCS, Figure $5(13))$. For the purposes of this analysis, we grouped the six pictures into four categories: underweight (corresponding to BCS 3 or lower); ideal (corresponding to BCS 4-5); overweight (corresponding to BCS 6); and obese (corresponding to BCS 7 or higher). Since owners have been reported to systematically misperceive body condition scores (34) we validated these scores against current and ideal body weights reported by a subset of respondents. Owner-reported BCS showed strong correspondence with owner-reported current-to-ideal body weight ratios. Using suggested ratio guidelines of $>1.15$ for overweightness and $>1.30$ for obesity (1) we calculated sensitivity (the proportion of overweight dogs by weight ratio correctly selected as overweight by BCS) and specificity (the proportion of ideal weight dogs by weight ratio correctly selected as ideal by BCS). We calculated $90 \%$ sensitivity and $79 \%$ specificity for overweightness/obesity, and $57 \%$ sensitivity and $94 \%$ specificity for obesity. Hence, dogs with BCS >= 6 are referred to as "overweight" and those with BCS >=7 as "obese."

\section{$\underline{\text { Diet }}$}

Owners were asked to check a box for each food type currently being fed, with multiple selections allowed. The final binned categories consisted of canned food, dry food (kibble), raw with home-prepared raw foods, dehydrated with freeze-dried foods, and commercial fresh/frozen with home-cooked foods. The seven most common combinations of diets were identified to be dry food only ( $N=938)$, canned food only ( $N=182)$, fresh food only $(N=1,001)$, dry plus canned food $(N=349)$, dry plus fresh food $(N=376)$, dehydrated/freeze-dried only ( $N=109)$, raw only $(\mathrm{N}=136)$, and other configurations of these same elements $(N=1,355)$; these diets were coded as factors and entered into the model as such. We did not ask for proportions of these dietary elements.

\section{$\underline{\text { Data analysis }}$}

For each of the variable selection procedures, two models were run: the first to differentiate ideal weight dogs from overweight and obese dogs, and the second to differentiate ideal weight dogs from the smaller subset of dogs reported to be obese. The statistical significance for all variable selection procedures was set at $a=0.05$.

Univariate Analysis: Univariate associations between BCS and each of the 45 variables under consideration were examined. We performed chi-square tests for binary variables, t-tests for continuous variables, and ANOVA for categorical/ordinal variables, including arguably ordered factors such as 
exercise and treats, due to the possibility of non-linear effects. We did not correct for multiple comparisons in this analysis, in order to obtain a fuller, more descriptive, model of potential associations.

Method 1: Logistic Regression with Stepwise Selection: A logistic model was fit using variables selected through bidirectional stepwise selection using StepAIC in R. However, given the statistical issues raised around traditional stepwise selection, including the use of Monte Carlo simulations to show how infrequently all correct explanatory variables are selected during data mining (35), two additional methods were used to identify ensembles of risk factors, which were then entered into a traditional logistic regression to maximize interpretability.

Method 2: Elastic Net Selection: ElasticNetCV from the sklearn package was used to select the parameters $\lambda$ and $a$, which control the level of penalty and the relative ratio of $L_{1}$ and $L_{2}$ penalties (39). Twenty iterations of Elastic Net were run using all variables, and the most important variables selected by Elastic Net were used to fit a logistic regression model to maximize interpretability. For both the overweight/obese and obese models, the best ensemble of risk factors was selected by consecutively adding variables and performing ANOVAs with significance tests to assess the contribution of each additional variable in the nested model, continuing the process until reaching a variable that did not significantly improve the model. Note that this differs from the true stepwise selection procedure performed before, in that the variables are added in order of importance in the complete model, rather than by their additive contribution to the partial model.

Method 3: XGBoost Selection: A grid search using GridSearchCV() was used to identify parameter values. Twenty iterations of XGBoost were run using all variables, and variable importance was averaged across iterations. The most important variables were entered stepwise into a logistic regression model until subsequent entered variables failed to significantly improve the predictive ability of the model as detailed for Elastic Net.

Data Imputation: Since not all survey questions were required, the 45 variables used in the analysis had between 0-4.5\% missing data, which were inferred via imputation using MissForest() in R (40). Missingness and out-of-box imputation accuracy are provided for each of the variables in [Additional File 6]. Variables with over $5 \%$ missingness were excluded from analysis. Once variables were identified as important through the variable selection methods delineated above, the final logistic regression model was fit using only complete cases so as to avoid inaccurate or biased model fit values.

Univariate analysis, imputation, stepwise selection, and logistic regressions were conducted in $\mathrm{R}$ version 3.5.2. Elastic Net and XGBoost were conducted in Python version 3.6.7.

\section{Declarations}

\section{Ethics statement:}


This study was carried out in accordance with the recommendations of the Federal Policy for the Protection of Human Subjects, U.S. Department of Health and Human Services. Since our study gathered information from owners focused solely on their dogs it does not meet the definition of human subjects research and therefore did not require review by an Institutional Review Board.

\section{Consent for publication:}

Survey respondents agreed to a Terms of Service (TOS) consenting to using pet information for research and publication. Furthermore, all the data in this study has been deidentified.

\section{Availability of data and materials:}

The deidentified datasets generated and/or analyzed during the current study are not publicly available since they are generated for proprietary business and marketing purposes, but are available from the corresponding author upon reasonable request.

\section{Competing interests:}

LP, JS, JT, DM, RH, and AJ received compensation from NomNomNow, Inc. during the collection and publication of the data herein.

\section{Funding:}

The design of the study and collection, analysis, and interpretation of data and writing the manuscript was funded by NomNomNow, Inc. through the employment of the authors. No additional funding was required.

\section{Authors' contributions:}

LP conceived the scope of the work, analyzed and interpreted the data, drafted the manuscript, and created figures and tables. JS designed the survey questions and reviewed the findings and manuscript. JT interpreted the data and critically reviewed the manuscript. DM implemented the owner-reported assessment questions. RH conceived the scope of the work, designed the survey questions, and reviewed the findings and the manuscript. AJ conceived the scope of the work, interpreted the data, and reviewed the findings and the manuscript.

\section{Acknowledgements:}

The authors would like to thank the NomNomNow, Inc. Scientific Advisory Board for their thoughtful consideration and helpful discussion regarding data analysis and interpretation. We are grateful to our survey participants for providing us with the data on their dogs.

\section{References}


1. German AJ. The growing problem of obesity in dogs and cats. J Nutr. 2006 Jul;136(7 Suppl):1940S - 1946S.

2. Salt C, Morris PJ, Wilson D, Lund EM, German AJ. Association between life span and body condition in neutered client-owned dogs. J Vet Intern Med. 2019 Jan;33(1):89-99.

3. Lund EM, Armstrong PJ, Kirk CA, Klausner JS. Prevalence and risk factors for obesity in adult dogs from private US veterinary practices. Int J Appl Res Vet Med. 2006;4(2):177.

4. Muñoz-Prieto A, Nielsen LR, Dąbrowski R, Bjørnvad CR, Söder J, Lamy E, et al. European dog owner perceptions of obesity and factors associated with human and canine obesity. Sci Rep. 2018 Sep 6;8(1):13353.

5. Mao J, Xia Z, Chen J, Yu J. Prevalence and risk factors for canine obesity surveyed in veterinary practices in Beijing, China. Prev Vet Med. 2013 Nov 1;112(3-4):438-42.

6. Usui S, Yasuda H, Koketsu Y. Characteristics of obese or overweight dogs visiting private Japanese veterinary clinics. Asian Pac J Trop Biomed. 2016 Apr 1;6(4):338-43.

7. Gates MC, Zito S, Harvey LC, Dale A, Walker JK. Assessing obesity in adult dogs and cats presenting for routine vaccination appointments in the North Island of New Zealand using electronic medical records data. N Z Vet J. 2019 May;67(3):126-33.

8. Courcier EA, Thomson RM, Mellor DJ, Yam PS. An epidemiological study of environmental factors associated with canine obesity. J Small Anim Pract. 2010 Jul;51(7):362-7.

9. McGreevy PD, Thomson PC, Pride C, Fawcett A, Grassi T, Jones B. Prevalence of obesity in dogs examined by Australian veterinary practices and the risk factors involved. Vet Rec. 2005 May 28;156(22):695-702.

10. Bjørnvad CR, Gloor S, Johansen SS, Sandøe P, Lund TB. Neutering increases the risk of obesity in male dogs but not in bitches - A cross-sectional study of dog- and owner-related risk factors for obesity in Danish companion dogs. Prev Vet Med. 2019 Oct 1;170:104730.

11. Robertson ID. The association of exercise, diet and other factors with owner-perceived obesity in privately owned dogs from metropolitan Perth, WA. Prev Vet Med. 2003 Apr 30;58(1-2):75-83.

12. Sallander $M$, Hagberg $M$, Hedhammar A, Rundgren M, Lindberg JE. Energy-intake and activity risk factors for owner-perceived obesity in a defined population of Swedish dogs. Prev Vet Med. 2010 Aug 1;96(1-2):132-41.

13. Laflamme, D. (Ralston Purina Company, St. Louis, MO. ). Development and validation of a body condition score system for dogs. Canine Pract [Internet]. jul-aug1997;22. Available from: http://agris.fao.org/agris-search/search.do?recordID=US9742264

14. Zhou D-X. On grouping effect of elastic net. Stat Probab Lett. 2013 Sep 1;83(9):2108-12.

15. Chen T, Guestrin C. XGBoost: A Scalable Tree Boosting System. In: Proceedings of the 22nd ACM SIGKDD International Conference on Knowledge Discovery and Data Mining - KDD '16. New York, New York, USA: ACM Press; 2016. p. 785-94. 
16. Leon AC, Heo M. Sample Sizes Required to Detect Interactions between Two Binary Fixed-Effects in a Mixed-Effects Linear Regression Model. Comput Stat Data Anal. 2009 Jan 15;53(3):603-8.

17. Warren BS, Wakshlag JJ, Maley M, Farrell TJ, Struble AM, Panasevich MR, et al. Use of pedometers to measure the relationship of dog walking to body condition score in obese and non-obese dogs. $\mathrm{Br} \mathrm{J}$ Nutr. 2011 Oct;106 Suppl 1:S85-9.

18. Jeusette I, Detilleux J, Cuvelier C, Istasse L, Diez M. Ad libitum feeding following ovariectomy in female Beagle dogs: effect on maintenance energy requirement and on blood metabolites. $J$ Anim Physiol Anim Nutr . 2004 Apr;88(3-4):117-21.

19. Rowe E, Browne W, Casey R, Gruffydd-Jones T, Murray J. Risk factors identified for owner-reported feline obesity at around one year of age: Dry diet and indoor lifestyle. Prev Vet Med. 2015 Oct $1 ; 121(3-4): 273-81$.

20. Wall M, Cave NJ, Vallee E. Owner and Cat-Related Risk Factors for Feline Overweight or Obesity. Front Vet Sci. 2019 Aug 19;6:266.

21. Coe JB, Rankovic A, Edwards TR, Parr JM. Dog owner's accuracy measuring different volumes of dry dog food using three different measuring devices. Vet Rec [Internet]. 2019 Aug 13; Available from: http://dx.doi.org/10.1136/vr.105319

22. Freeman LM, Chandler ML, Hamper BA, Weeth LP. Current knowledge about the risks and benefits of raw meat-based diets for dogs and cats. J Am Vet Med Assoc. 2013 Dec 1;243(11):1549-58.

23. Forster GM, Stockman J, Noyes N, Heuberger AL, Broeckling CD, Bantle CM, et al. A Comparative Study of Serum Biochemistry, Metabolome and Microbiome Parameters of Clinically Healthy, Normal Weight, Overweight, and Obese Companion Dogs. Top Companion Anim Med. 2018 Dec;33(4):12635.

24. Ejtahed H-S, Angoorani P, Soroush A-R, Atlasi R, Hasani-Ranjbar S, Mortazavian AM, et al. Probiotics supplementation for the obesity management; A systematic review of animal studies and clinical trials. J Funct Foods. 2019 Jan 1;52:228-42.

25. Koutnikova H, Genser B, Monteiro-Sepulveda M, Faurie J-M, Rizkalla S, Schrezenmeir J, et al. Impact of bacterial probiotics on obesity, diabetes and non-alcoholic fatty liver disease related variables: a systematic review and meta-analysis of randomised controlled trials. BMJ Open. 2019 Mar 30;9(3):e017995.

26. Mazloom K, Siddiqi I, Covasa M. Probiotics: How Effective Are They in the Fight against Obesity? Nutrients. 2019 Jan 24;11(2):258.

27. Kim YA, Keogh JB, Clifton PM. Probiotics, prebiotics, synbiotics and insulin sensitivity. Nutr Res Rev. 2018 Jun;31(1):35-51.

28. Raffan E, Smith SP, O'Rahilly S, Wardle J. Development, factor structure and application of the Dog Obesity Risk and Appetite (DORA) questionnaire. PeerJ. 2015 Sep 29;3:e1278.

29. Pogány Á, Torda O, Marinelli L, Lenkei R, Junó V, Pongrácz P. The behaviour of overweight dogs shows similarity with personality traits of overweight humans. R Soc Open Sci. 2018 Jun;5(6):172398. 
30. Luño I, Palacio J, García-Belenguer S, González-Martínez Á, Rosado B. Emotional eating in companion dogs: Owners' perception and relation with feeding habits, eating behavior, and emotional state. J Vet Behav. 2018 May 1;25:17-23.

31. Tiira K, Hakosalo O, Kareinen L, Thomas A, Hielm-Björkman A, Escriou C, et al. Environmental effects on compulsive tail chasing in dogs. PLoS One. 2012 Jul 26;7(7):e41684.

32. Voigt J-P, Fink H. Serotonin controlling feeding and satiety. Behav Brain Res. 2015 Jan 15;277:1431.

33. Moon-Fanelli AA, Dodman NH. Description and development of compulsive tail chasing in terriers and response to clomipramine treatment. J Am Vet Med Assoc. 1998 Apr 15;212(8):1252-7.

34. Eastland-Jones RC, German AJ, Holden SL, Biourge V, Pickavance LC. Owner misperception of canine body condition persists despite use of a body condition score chart. J Nutr Sci. 2014 Oct 8;3:e45.

35. Smith G. Step away from stepwise. Journal of Big Data. 2018 Sep 15;5(1):32.

36. Mawby DI, Bartges JW, d'Avignon A, Laflamme DP, Moyers TD, Cottrell T. Comparison of various methods for estimating body fat in dogs. J Am Anim Hosp Assoc. 2004 Mar;40(2):109-14.

37. Colliard L, Ancel J, Benet J-J, Paragon B-M, Blanchard G. Risk factors for obesity in dogs in France. J Nutr. 2006 Jul;136(7 Suppl):1951S - 1954S.

38. Gossellin J, Wren JA, Sunderland SJ. Canine obesity: an overview. J Vet Pharmacol Ther. 2007 Aug;30 Suppl 1:1-10.

39. Pedregosa F. Scikit-learn: Machine Learning in Python. J Mach Learn Res. 2011;12:2825-30.

40. Stekhoven DJ, Bühlmann P. MissForest-non-parametric missing value imputation for mixed-type data. Bioinformatics. 2012 Jan 1;28(1):112-8.

\section{Tables}




\section{Table 1: Results of Univariate Analyses}

\begin{tabular}{|c|c|c|c|c|c|c|c|}
\hline & & \multicolumn{3}{|c|}{$\begin{array}{l}\text { Overweight and Obese }(\mathrm{N}=1480) \text { vs Ideal } \\
\qquad(\mathrm{N}=2966)\end{array}$} & \multicolumn{3}{|c|}{ Obese $(\mathrm{N}=356)$ vs Ideal $(\mathrm{N}=2966)$} \\
\hline & & $\begin{array}{c}\mathrm{N}(\% \text { of } 4,446) \text { or } \\
\text { mean }(\mathrm{SD})\end{array}$ & $\begin{array}{l}\text { OR }[95 \% \\
\mathrm{CI}]\end{array}$ & $\mathrm{p}$ & $\begin{array}{l}\text { N (\% of } 3,322) \\
\text { or mean }(\mathrm{SD})\end{array}$ & $\begin{array}{l}\text { OR }[95 \% \\
\mathrm{CI}]\end{array}$ & $\mathrm{p}$ \\
\hline \multirow[t]{8}{*}{ Diet } & Fresh Only & $1,001(22 \%)$ & \multicolumn{2}{|c|}{ Reference } & $761(23 \%)$ & \multicolumn{2}{|c|}{ Reference } \\
\hline & Kibble Only & $938(21 \%)$ & $\begin{array}{l}1.45 \\
{[1.21-} \\
1.76]\end{array}$ & $<0.0001^{* * *}$ & $684(21 \%)$ & $\begin{array}{l}2.11 \\
{[1.52-} \\
2.96]\end{array}$ & $<0.0001 * * *$ \\
\hline & Kibble \& Fresh & $376(8.5 \%)$ & $\begin{array}{l}1.31 \\
{[1.02-} \\
1.68]\end{array}$ & $0.03 *$ & $263(7.9 \%)$ & $\begin{array}{l}1.08 \\
{[0.64-} \\
1.76]\end{array}$ & $>0.05$ \\
\hline & $\begin{array}{l}\text { Kibble \& } \\
\text { Canned }\end{array}$ & 349 (7.9\%) & $\begin{array}{l}1.85 \\
{[1.44-} \\
2.38]\end{array}$ & $<0.0001 * * *$ & $238(7.2 \%)$ & $\begin{array}{l}2.56 \\
{[1.68-} \\
3.87]\end{array}$ & $<0.0001 * * *$ \\
\hline & Canned Only & $182(4.1 \%)$ & $\begin{array}{l}1.31 \\
{[0.94-} \\
1.83]\end{array}$ & $>0.05$ & $134(4.0 \%)$ & $\begin{array}{l}1.75 \\
{[0.97-} \\
3.01]\end{array}$ & $>0.05$ \\
\hline & Raw Only & $136(3.1 \%)$ & $\begin{array}{l}0.52 \\
{[0.32-} \\
0.81]\end{array}$ & $0.005^{* *}$ & $116(3.5 \%)$ & $\begin{array}{l}0.51 \\
{[0.17-} \\
1.17]\end{array}$ & $>0.05$ \\
\hline & Dried Only & $109(2.5 \%)$ & $\begin{array}{l}0.84 \\
{[0.53-} \\
1.30]\end{array}$ & $>0.05$ & $86(2.6 \%)$ & $\begin{array}{l}0.85 \\
{[0.32-} \\
1.87]\end{array}$ & $>0.05$ \\
\hline & Other/Unknown & $1,355(30 \%)$ & $\begin{array}{l}0.98 \\
{[0.82-} \\
1.18]\end{array}$ & $>0.05$ & $1,040(31 \%)$ & $\begin{array}{l}1.06 \\
{[0.75-} \\
1.49]\end{array}$ & $>0.05$ \\
\hline \multirow[t]{3}{*}{ Treats } & None & 325 (7.3\%) & \multicolumn{2}{|c|}{ Reference } & $262(7.9 \%)$ & \multicolumn{2}{|c|}{ Reference } \\
\hline & $<10$ percent & $3,535(80 \%)$ & $\begin{array}{l}1.13 \\
{[0.88-} \\
1.46]\end{array}$ & $>0.05$ & $2,655(80 \%)$ & $\begin{array}{l}0.72 \\
{[0.49-} \\
1.09]\end{array}$ & $>0.05$ \\
\hline & $>10$ percent & $581(13 \%)$ & $\begin{array}{l}2.12 \\
{[1.59-} \\
2.84]\end{array}$ & $<0.0001^{* * *}$ & 402 (12\%) & $\begin{array}{l}2.15 \\
{[1.40-} \\
3.39]\end{array}$ & $0.0007 * * *$ \\
\hline \multirow[t]{2}{*}{ Probiotics } & No & $3,602(81 \%)$ & \multicolumn{2}{|c|}{ Reference } & 2,658 (80\%) & \multicolumn{2}{|c|}{ Reference } \\
\hline & Yes & 844 (19\%) & $\begin{array}{l}0.65 \\
{[0.55-} \\
0.77]\end{array}$ & $<0.0001^{* * *}$ & 664 (20\%) & $\begin{array}{l}0.46 \\
{[0.32-} \\
0.64]\end{array}$ & $<0.0001 * * *$ \\
\hline Age & Years & 6.73 (4.09) & $\begin{array}{l}1.09 \\
{[1.07-} \\
1.11]\end{array}$ & $<0.0001 * * *$ & $6.44(4.16)$ & $\begin{array}{l}1.10 \\
{[1.07-} \\
1.13]\end{array}$ & $<0.0001^{* * *}$ \\
\hline
\end{tabular}




\begin{tabular}{|c|c|c|c|c|c|c|c|}
\hline \multirow{2}{*}{$\begin{array}{l}\text { Exercise per } \\
\text { week }\end{array}$} & \multirow{2}{*}{$\begin{array}{l}0-4 \text { hours } \\
\text { 4-7 hours }\end{array}$} & \multirow{2}{*}{$\begin{array}{l}1,827(41 \%) \\
1,549(35 \%)\end{array}$} & \multicolumn{2}{|c|}{ Reference } & \multirow{2}{*}{$\begin{array}{l}1,296(39 \%) \\
1,160(35 \%)\end{array}$} & \multicolumn{2}{|c|}{ Reference } \\
\hline & & & $\begin{array}{l}0.57 \\
{[0.50-} \\
0.66]\end{array}$ & $<0.0001 * * *$ & & $\begin{array}{l}0.28 \\
{[0.21-} \\
0.37]\end{array}$ & $<0.0001^{* * *}$ \\
\hline & 7-14 hours & 804 (18\%) & $\begin{array}{l}0.45 \\
{[0.37-} \\
0.54]\end{array}$ & $<0.0001^{* * *}$ & 639 (19\%) & $\begin{array}{l}0.25 \\
{[0.17-} \\
0.35]\end{array}$ & $<0.0001 * * *$ \\
\hline & $14+$ hours & 257 (5.8\%) & $\begin{array}{l}0.29 \\
{[0.20-} \\
0.40]\end{array}$ & $<0.0001 * * *$ & 221 (6.7\%) & $\begin{array}{l}0.19 \\
{[0.09-} \\
0.35]\end{array}$ & $<0.0001^{* * *}$ \\
\hline \multirow[t]{2}{*}{ Neutered } & No & 524 (12\%) & \multicolumn{2}{|c|}{ Reference } & 449 (14\%) & \multicolumn{2}{|c|}{ Reference } \\
\hline & Yes & 3,904 (88\%) & $\begin{array}{l}2.39 \\
{[1.90-} \\
3.02]\end{array}$ & $<0.0001 * * *$ & 2,864 (86\%) & $\begin{array}{l}2.54 \\
{[1.67-} \\
4.08]\end{array}$ & $<0.0001 * * *$ \\
\hline Pet Appetite & 1-5 scale & $1.90(0.46)$ & $\begin{array}{l}2.16 \\
{[1.86-} \\
2.51]\end{array}$ & $<0.0001^{* * *}$ & $1.88(0.46)$ & $\begin{array}{l}4.30 \\
{[3.28-} \\
5.67]\end{array}$ & $<0.0001^{* * *}$ \\
\hline $\begin{array}{l}\text { Food } \\
\text { Motivation }\end{array}$ & 1-5 scale & $4.00(1.26)$ & $\begin{array}{l}1.23 \\
{[1.16-} \\
1.30]\end{array}$ & $<0.0001^{* * *}$ & $3.95(1.28)$ & $\begin{array}{l}1.40 \\
{[1.26-} \\
1.56]\end{array}$ & $<0.0001^{* * *}$ \\
\hline Mood & $1-5$ scale & $1.91(0.93)$ & $\begin{array}{l}1.30 \\
{[1.21-} \\
1.38]\end{array}$ & $<0.0001^{* * *}$ & $1.88(0.93)$ & $\begin{array}{l}1.50 \\
{[1.34-} \\
1.67]\end{array}$ & $<0.0001^{* * *}$ \\
\hline $\begin{array}{l}\text { Conspecific } \\
\text { Interaction }\end{array}$ & 1-4 scale & $2.67(0.94)$ & $\begin{array}{l}0.81 \\
{[0.75-} \\
0.86]\end{array}$ & $<0.0001^{* * *}$ & $2.70(0.94)$ & $\begin{array}{l}0.71 \\
{[0.63-} \\
0.81]\end{array}$ & $<0.0001^{* * *}$ \\
\hline Tail Chasing & 1-5 scale & $4.74(0.74)$ & $\begin{array}{l}1.24 \\
{[1.13-} \\
1.36]\end{array}$ & $<0.0001^{* * *}$ & $4.73(0.76)$ & $\begin{array}{l}1.54 \\
{[1.25-} \\
1.97]\end{array}$ & $0.0001^{* * *}$ \\
\hline Prey Drive & 1-5 scale & $2.67(1.29)$ & $\begin{array}{l}0.91 \\
{[0.87-} \\
0.96]\end{array}$ & $0.0003^{* * *}$ & $2.69(1.30)$ & $\begin{array}{l}0.83 \\
{[0.76-} \\
0.91]\end{array}$ & $<0.0001 * * *$ \\
\hline \multirow[t]{2}{*}{ Other Dogs } & No & 2,361 (53\%) & \multicolumn{2}{|c|}{ Reference } & 1,775 (53\%) & \multicolumn{2}{|c|}{ Reference } \\
\hline & Yes & 2,085 (47\%) & $\begin{array}{l}1.26 \\
{[1.11-} \\
1.43]\end{array}$ & $0.0003^{* * *}$ & $1,547(47 \%)$ & $\begin{array}{l}1.81 \\
{[1.45-} \\
2.27]\end{array}$ & $<0.0001^{* * *}$ \\
\hline \multirow[t]{2}{*}{ Dental Chews } & No & $2,786(63 \%)$ & \multicolumn{2}{|c|}{ Reference } & $2,120(64 \%)$ & \multicolumn{2}{|c|}{ Reference } \\
\hline & Yes & $1,660(37 \%)$ & $\begin{array}{l}1.24 \\
{[1.09-} \\
1.41]\end{array}$ & $0.001^{* *}$ & 1,202 (36\%) & $\begin{array}{l}1.23 \\
{[0.98-} \\
1.54]\end{array}$ & $>0.05$ \\
\hline Share & No & $1,768(40 \%)$ & & rence & $1,362(41 \%)$ & & rence \\
\hline
\end{tabular}

Page 18/31 


\begin{tabular}{|c|c|c|c|c|c|c|c|}
\hline \multicolumn{8}{|l|}{ Food/Cook } \\
\hline & Yes & $2,668(60 \%)$ & $\begin{array}{l}1.24 \\
{[1.09-} \\
1.41]\end{array}$ & $0.001 * *$ & 1,953 (59\%) & $\begin{array}{l}1.19 \\
{[0.95-} \\
1.50]\end{array}$ & $>0.05$ \\
\hline \multirow{3}{*}{$\begin{array}{l}\text { Home } \\
\text { Environment }\end{array}$} & Urban & $1,048(24 \%)$ & \multicolumn{2}{|c|}{ Reference } & 813 (24\%) & \multicolumn{2}{|c|}{ Reference } \\
\hline & Suburban & $2,736(62 \%)$ & $\begin{array}{l}1.22 \\
{[1.05-} \\
1.43]\end{array}$ & $0.009 * *$ & 2,017 (61\%) & $\begin{array}{l}1.16 \\
{[0.88-} \\
1.53]\end{array}$ & $>0.05$ \\
\hline & Rural & 648 (15\%) & $\begin{array}{l}1.36 \\
{[1.11-} \\
1.68]\end{array}$ & $0.003 * *$ & 480 (14\%) & $\begin{array}{l}1.62 \\
{[1.14-} \\
2.30]\end{array}$ & $0.007^{* *}$ \\
\hline \multirow[t]{3}{*}{ Medicine Type } & $\begin{array}{l}\text { Conventional } \\
\text { Only }\end{array}$ & 1,621 (36\%) & \multicolumn{2}{|c|}{ Reference } & $1,202(36 \%)$ & \multicolumn{2}{|c|}{ Reference } \\
\hline & Mixed & 2,602 (59\%) & $\begin{array}{l}0.84 \\
{[0.74-} \\
0.96]\end{array}$ & $0.01 *$ & 1,949 (59\%) & $\begin{array}{l}0.65 \\
{[0.52-} \\
0.82]\end{array}$ & $0.0002 * * *$ \\
\hline & Holistic Only & 176 (4.0\%) & $\begin{array}{l}0.67 \\
{[0.47-} \\
0.95]\end{array}$ & $0.03 *$ & 138 (4.2\%) & $\begin{array}{l}0.51 \\
{[0.25-} \\
0.94]\end{array}$ & $0.04 *$ \\
\hline Nervousness & 1-5 scale & $2.36(1.21)$ & $\begin{array}{l}1.06 \\
{[1.01-} \\
1.12]\end{array}$ & $0.02 *$ & $2.34(1.20)$ & $\begin{array}{l}1.09 \\
{[0.99-} \\
1.19]\end{array}$ & $>0.05$ \\
\hline \multirow{2}{*}{$\begin{array}{l}\text { Household } \\
\text { Tobacco }\end{array}$} & No & 4,098 (92\%) & \multicolumn{2}{|c|}{ Reference } & $3,070(92 \%)$ & \multicolumn{2}{|c|}{ Reference } \\
\hline & Yes & 327 (7\%) & $\begin{array}{l}1.34 \\
{[1.06-} \\
1.69]\end{array}$ & $0.01 *$ & $236(7 \%)$ & $\begin{array}{l}1.69 \\
{[1.16-} \\
2.41]\end{array}$ & $0.005^{* *}$ \\
\hline $\begin{array}{l}\text { Dentist } \\
\text { Frequency }\end{array}$ & 1-3 scale & $1.56(0.73)$ & $\begin{array}{l}1.11 \\
{[1.02-} \\
1.21]\end{array}$ & $0.02 *$ & $1.55(0.73)$ & $\begin{array}{l}1.12 \\
{[0.97-} \\
1.30]\end{array}$ & $>0.05$ \\
\hline \multirow{2}{*}{$\begin{array}{l}\text { Food } \\
\text { Intolerances }\end{array}$} & No & $3,646(82 \%)$ & \multicolumn{2}{|c|}{ Reference } & $2,714(82 \%)$ & \multicolumn{2}{|c|}{ Reference } \\
\hline & Yes & 774 (18\%) & $\begin{array}{l}0.83 \\
{[0.70-} \\
0.98]\end{array}$ & $0.03 *$ & 591 (18\%) & $\begin{array}{l}0.70 \\
{[0.51-} \\
0.96]\end{array}$ & $0.03 *$ \\
\hline \multirow{2}{*}{$\begin{array}{l}\text { Acquisition } \\
\text { Method }\end{array}$} & Breeder & $1,930(43 \%)$ & \multicolumn{2}{|c|}{ Reference } & $1,470(44 \%)$ & \multicolumn{2}{|c|}{ Reference } \\
\hline & Rescue & $1,657(37 \%)$ & $\begin{array}{l}1.25 \\
{[1.09-} \\
1.44]\end{array}$ & $0.002 * *$ & $1,212(36 \%)$ & $\begin{array}{l}1.38 \\
{[1.07-} \\
1.78]\end{array}$ & $0.0002 * * *$ \\
\hline & Other & 859 (19\%) & 1.29 & $0.003 * *$ & 640 (19\%) & 1.75 & $0.01 *$ \\
\hline
\end{tabular}




\begin{tabular}{|l|l|l|l|l|l|}
{$\left[\begin{array}{l}{[1.09-} \\
1.53\end{array}\right.$} & & & $2.31-$ \\
$2.33]$ & \\
\hline
\end{tabular}

OR: Odds Ratio; 95\% CI: 95\% Confidence Interval; Pet Appetite: 1-Poor, 5-Excellent; Food Motivation Level: 1-Not at all, 5-Very; Mood: 1-Excellent, 5-Depressed; Conspecific Interaction: 1-Never, 4-Often; Tail Chasing Frequency: 1-Never, 5-Multiple times per day; Prey Drive: 1-Never, 5-Very Often; Nervousness: 1-Not at all, 5-Very; Dentist Frequency: 1-Never, 3-Three or more times 
Table 2: Final Multivariable Logistic Regression Models

\begin{tabular}{|c|c|c|c|c|c|}
\hline \multirow[b]{2}{*}{ Feature } & & \multicolumn{2}{|c|}{$\begin{array}{l}\text { Overweight and Obese }(\mathrm{N}=1384) \text { vs Ideal } \\
(\mathrm{N}=2725)\end{array}$} & \multicolumn{2}{|c|}{$\begin{array}{l}\text { Obese }(\mathrm{N}=327) \text { vs Ideal } \\
(\mathrm{N}=2725)\end{array}$} \\
\hline & & OR [95\% CI] & p-value & OR [95\% CI] & p-value \\
\hline \multirow[t]{2}{*}{ Age } & Years & $1.58[1.47-1.70][\mathrm{B}]$ & $<0.0001 * * *$ & $\begin{array}{l}1.82[1.56- \\
2.14]\end{array}$ & $<0.0001 * * *$ \\
\hline & Years $^{2}$ [A] & $0.98[0.97-0.98]$ & $<0.0001 * * *$ & $\begin{array}{l}0.97[0.96- \\
0.98]\end{array}$ & $<0.0001^{* * *}$ \\
\hline \multirow[t]{4}{*}{ Exercise per week } & $<4$ hours & \multicolumn{2}{|c|}{ Reference } & \multicolumn{2}{|c|}{ Reference } \\
\hline & 4-7 hours & $0.67[0.57-0.79]$ & $<0.0001 * * *$ & $\begin{array}{l}0.32[0.23- \\
0.44]\end{array}$ & $<0.0001 * * *$ \\
\hline & 7-14 hours & $0.58[0.47-0.71]$ & $<0.0001 * * *$ & $\begin{array}{l}0.33[0.21- \\
0.50]\end{array}$ & $<0.0001 * * *$ \\
\hline & $>14$ hours & $0.45[0.31-0.65]$ & $<0.0001 * * *$ & $\begin{array}{l}0.25[0.11- \\
0.57]\end{array}$ & $0.001 * * *$ \\
\hline \multirow[t]{8}{*}{ Diet Composition } & Fresh & \multicolumn{2}{|c|}{ Reference } & \multicolumn{2}{|c|}{ Reference } \\
\hline & Dry & $1.47[1.19-1.82]$ & $0.0003 * * *$ & $\begin{array}{l}2.17[1.47- \\
3.20]\end{array}$ & $0.0001 * * *$ \\
\hline & Canned & $1.11[0.77-1.61]$ & $>0.05$ & $\begin{array}{l}1.46[0.74- \\
2.89]\end{array}$ & $>0.05$ \\
\hline & $\begin{array}{l}\text { Dehydrated/ Freeze- } \\
\text { Dried }\end{array}$ & $0.88[0.54-1.43]$ & $>0.05$ & $\begin{array}{l}0.65[0.22- \\
1.87]\end{array}$ & $>0.05$ \\
\hline & Raw & $0.57[0.35-0.93]$ & $0.02 *$ & $\begin{array}{l}0.52[0.19- \\
1.44]\end{array}$ & $>0.05$ \\
\hline & Kibble and Canned & $1.93[1.46-2.56]$ & $<0.0001 * * *$ & $\begin{array}{l}2.64[1.60- \\
4.34]\end{array}$ & $0.0001 * * *$ \\
\hline & Kibble and Fresh & $1.47[1.11-1.95]$ & $0.007 * *$ & $\begin{array}{l}1.38[0.77- \\
2.47]\end{array}$ & $>0.05$ \\
\hline & Other Combination & $1.06[0.87-1.30]$ & $>0.05$ & $\begin{array}{l}1.17[0.78- \\
1.75]\end{array}$ & $>0.05$ \\
\hline Food Motivation Level & $1-5$ scale & $1.18[1.11-1.26]$ & $<0.0001 * * *$ & $\begin{array}{l}1.33[1.17- \\
1.50]\end{array}$ & $<0.0001 * * *$ \\
\hline Other Dogs & & ns & ns & $\begin{array}{l}1.78[1.36- \\
2.34]\end{array}$ & $<0.0001 * * *$ \\
\hline Overall Mood & 1-5 scale & $1.23[1.14-1.33]$ & $<0.0001 * * *$ & $\begin{array}{l}1.42[1.23- \\
1.63]\end{array}$ & $<0.0001 * * *$ \\
\hline Pet Appetite & 1-5 scale & 2.07 [1.75-2.45] & $<0.0001 * * *$ & $\begin{array}{l}4.36[3.13- \\
6.08]\end{array}$ & $<0.0001^{* * *}$ \\
\hline
\end{tabular}




\begin{tabular}{|c|c|c|c|c|c|}
\hline Share Food or Cook & & $1.19[1.02-1.38]$ & $0.03 *$ & ns & ns \\
\hline Neutered & & $1.66[1.28-2.17]$ & $0.0002 * * *$ & $\begin{array}{l}2.15[1.23- \\
3.76]\end{array}$ & $0.007 * *$ \\
\hline $\begin{array}{l}\text { Dental Treatment } \\
\text { Frequency }\end{array}$ & 1-3 scale & $0.82[0.73-0.91]$ & $0.0002 * * *$ & $\begin{array}{l}0.72[0.59- \\
0.88]\end{array}$ & $0.001 * *$ \\
\hline Tail Chasing Frequency & 1-5 scale & ns & ns & $\begin{array}{l}1.30[1.01- \\
1.69]\end{array}$ & $0.04 *$ \\
\hline \multirow[t]{3}{*}{ Treats Quantity } & None & \multicolumn{2}{|c|}{ Reference } & \multicolumn{2}{|c|}{ Reference } \\
\hline & Less than $10 \%$ & $1.25[0.95-1.66]$ & $>0.05$ & $\begin{array}{l}1.03[0.63- \\
1.69]\end{array}$ & $>0.05$ \\
\hline & More than $10 \%$ & $2.50[1.80-3.48]$ & $<0.0001 * * *$ & $\begin{array}{l}3.97[2.27- \\
6.95]\end{array}$ & $<0.0001^{* * *}$ \\
\hline Supplements Probiotic & & $0.72[0.60-0.87]$ & $<0.0001 * * *$ & $\begin{array}{l}0.57[0.38- \\
0.85]\end{array}$ & $0.006^{* *}$ \\
\hline \multirow[t]{3}{*}{ Medicine Type } & Conventional & \multicolumn{2}{|c|}{ Reference } & \multicolumn{2}{|c|}{ Reference } \\
\hline & Integrative & ns & ns & $\begin{array}{l}0.67[0.51- \\
0.88]\end{array}$ & $0.004 * *$ \\
\hline & Holistic & ns & ns & $\begin{array}{l}0.73[0.33- \\
1.59]\end{array}$ & $>0.05$ \\
\hline \multirow[t]{3}{*}{ Home Environment } & Urban & \multicolumn{2}{|c|}{ Reference } & \multicolumn{2}{|c|}{ Reference } \\
\hline & Suburban & $1.21[1.02-1.44]$ & $0.03 *$ & ns & ns \\
\hline & Rural & $1.35[1.07-1.72]$ & $0.01 *$ & ns & ns \\
\hline
\end{tabular}

OR: Odds Ratio; 95\% CI: 95\% Confidence Interval; Food Motivation Level: 1-Not at all, 5-Very; Mood: 1-Excellent, 5-Depressed; Pet Appetite: 1-Poor, 5-Excellent; Dental Frequency: 1-Never, 3-Three or more times; Tail Chasing Frequency: 1-Never, 5-Multiple times per day

[A] Age as a quadratic term was eliminated from the confirmatory variable selection procedures to maximize interpretability. Note also that XGBoost already handles nonlinearities in the input features through the potential selection of multiple decision points per variable.

[B] The coefficient of quadratic terms denotes the curvature. In this case the negative coefficient indicates that the curve is concave, with dogs in the middle of the age range at highest

\section{Table 3: Significant variables selected by each protocol}




\section{Overweightness/Obesity Obesity}

Univariate Stepwise Elastic Net XGBoost Univariate $\begin{gathered}\text { Stepwise } \\ \text { Elastic XGBoost } \\ \text { Net }\end{gathered}$

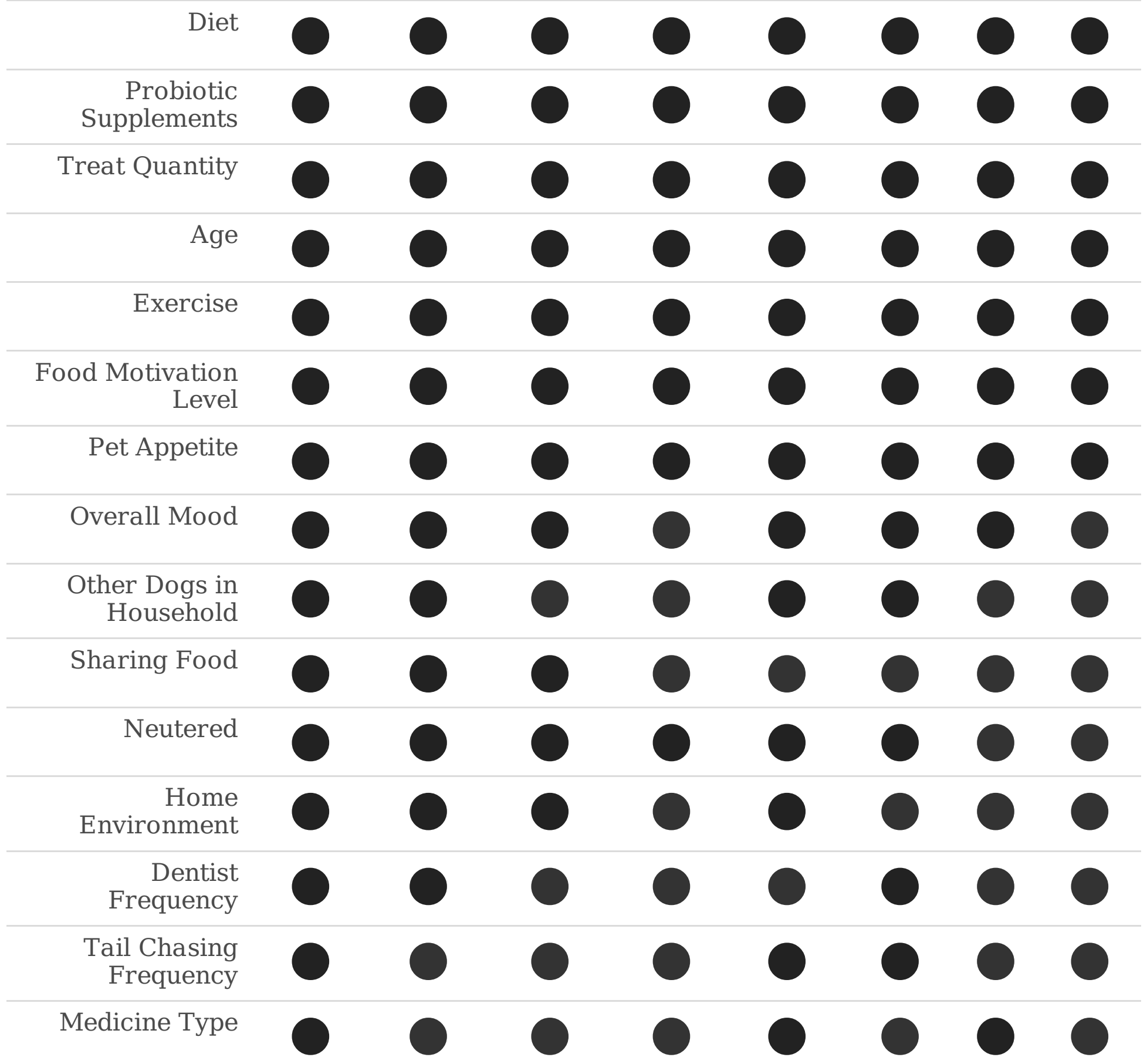

- $p<0.05, \bigcirc p>0.05$, Variables were included if they were significant in at least two different models. 
Table 4: Final Multivariable Logistic Regression Models for the Subgroup Without Major Medical Conditions

\begin{tabular}{|c|c|c|c|c|c|}
\hline \multirow[b]{2}{*}{ Feature } & & \multicolumn{2}{|c|}{$\begin{array}{l}\text { Overweight and Obese }(\mathrm{N}=1004) \text { vs Ideal } \\
(\mathrm{N}=1977)\end{array}$} & \multicolumn{2}{|c|}{$\begin{array}{l}\text { Obese }(\mathrm{N}=246) \text { vs Ideal } \\
(\mathrm{N}=1977)\end{array}$} \\
\hline & & OR [95\% CI] & p-value & OR [95\% CI] & p-value \\
\hline \multirow[t]{2}{*}{ Age } & Years & $1.64[1.50-1.80]$ & $<0.0001 * * *$ & $1.95[1.61-2.37]$ & $<0.0001 * * *$ \\
\hline & Years $^{2}[\mathrm{~A}]$ & 0.97 [0.97-0.98] & $<0.0001 * * *$ & $0.96[0.95-0.98]$ & $<0.0001^{* * *}$ \\
\hline \multirow[t]{4}{*}{ Exercise per week } & $<4$ hours & \multicolumn{2}{|c|}{ Reference } & \multicolumn{2}{|c|}{ Reference } \\
\hline & 4-7 hours & $0.59[0.48-0.71]$ & $<0.0001 * * *$ & $0.27[0.18-0.39]$ & $<0.0001 * * *$ \\
\hline & 7-14 hours & $0.51[0.40-0.65]$ & $<0.0001 * * *$ & $0.24[0.14-0.40]$ & $<0.0001 * * *$ \\
\hline & $>14$ hours & 0.38 [024-0.59] & $<0.0001 * * *$ & $0.19[0.07-0.50]$ & $0.0007 * * *$ \\
\hline \multirow[t]{8}{*}{ Diet Composition } & Fresh & \multicolumn{2}{|c|}{ Reference } & \multicolumn{2}{|c|}{ Reference } \\
\hline & Dry & 1.48 [1.16-1.88] & $0.0001 * * *$ & $2.16[1.39-3.36]$ & $0.0006 * * *$ \\
\hline & Canned & $0.98[0.63-1.54]$ & $>0.05$ & $1.30[0.58-2.90]$ & $>0.05$ \\
\hline & $\begin{array}{l}\text { Dehydrated/ Freeze- } \\
\text { Dried }\end{array}$ & $0.72[0.41-1.25]$ & $>0.05$ & $0.48[0.14-1.65]$ & $>0.05$ \\
\hline & Raw & $0.61[0.36-1.04]$ & $>0.05$ & $0.44[0.14-1.43]$ & $>0.05$ \\
\hline & Kibble and Canned & 2.19 [1.59-3.03] & $0.0001 * * *$ & $3.08[1.75-5.42]$ & $<0.0001 * * *$ \\
\hline & Kibble and Fresh & $1.48[1.08-2.03]$ & $0.02 *$ & $1.54[0.81-2.93]$ & $>0.05$ \\
\hline & Other Combination & $1.01[0.79-1.31]$ & $>0.05$ & 0.99 [0.58-1.67] & $>0.05$ \\
\hline Food Motivation Level & 1-5 scale & 1.19 [1.10-1.28] & $<0.0001 * * *$ & $1.31[1.13-1.52]$ & $0.0003 * * *$ \\
\hline Other Dogs & & ns & ns & 1.86 [1.34-2.59] & $0.0002 * * *$ \\
\hline Overall Mood & 1-5 scale & 1.26 [1.15-1.39] & $<0.0001 * * *$ & $1.41[1.19-1.67]$ & $<0.0001 * * *$ \\
\hline Pet Appetite & 1-5 scale & $2.13[1.73-2.62]$ & $<0.0001 * * *$ & $4.83[3.19-7.29]$ & $0.0001 * * *$ \\
\hline Share Food or Cook & & 1.24 [1.03-1.48] & $0.02 *$ & ns & ns \\
\hline Neutered & & $2.12[1.45-3.09]$ & $<0.0001 * * *$ & $3.30[1.45-7.52]$ & $0.004 * *$ \\
\hline $\begin{array}{l}\text { Dental Treatment } \\
\text { Frequency }\end{array}$ & $1-3$ scale & $0.77[0.68-0.88]$ & $<0.0001 * * *$ & $0.68[0.54-0.87]$ & $0.002^{* *}$ \\
\hline Tail Chasing Frequency & $1-5$ scale & ns & ns & ns & ns \\
\hline \multirow[t]{3}{*}{ Treats Quantity } & None & \multicolumn{2}{|c|}{ Reference } & \multicolumn{2}{|c|}{ Reference } \\
\hline & Less than $10 \%$ & $1.15[0.81-1.64]$ & $>0.05$ & $0.98[0.53-1.83]$ & $>0.05$ \\
\hline & More than $10 \%$ & $2.50[1.66-3.76]$ & $<0.0001 * * *$ & $\begin{array}{l}5.36[2.66- \\
10.79]\end{array}$ & $<0.0001 * * *$ \\
\hline Supplements Probiotic & & $0.72[0.57-0.92$ & $0.01 *$ & 0.60 [0.37-0.99] & $0.04 *$ \\
\hline
\end{tabular}




\begin{tabular}{|l|l|l|l|l|l|}
\hline Medicine Type & Conventional & $\mathrm{ns}$ & $\mathrm{ns}$ & $\mathrm{ns}$ & $\mathrm{ns}$ \\
\hline & Integrative & $\mathrm{ns}$ & $\mathrm{ns}$ & $\mathrm{ns}$ & $\mathrm{ns}$ \\
\hline & Holistic & $\mathrm{ns}$ & $\mathrm{ns}$ & $\mathrm{ns}$ & $\mathrm{ns}$ \\
\hline Home Environment & Urban & \multicolumn{2}{|c|}{ Reference } & \multicolumn{2}{|c|}{ Reference } \\
\hline & Suburban & $1.17[0.95-1.44]$ & $>0.05$ & $\mathrm{~ns}$ & $\mathrm{~ns}$ \\
\hline & Rural & $1.35[1.02-1.79]$ & $0.03^{*}$ & $\mathrm{~ns}$ & $\mathrm{~ns}$ \\
\hline
\end{tabular}

OR: Odds Ratio; 95\% CI: 95\% Confidence Interval; Food Motivation Level: 1-Not at all, 5-Very; Mood: 1-Excellent, 5-Depressed; Pet Appetite: 1-Poor, 5-Excellent; Dental Frequency: 1-Never, 3-Three or more times; Tail Chasing Frequency: 1-Never, 5-Multiple times per day

[A] Age as a quadratic term was eliminated from the confirmatory variable selection procedures to maximize interpretability. Note also that XGBoost already handles nonlinearities in the input features through the potential selection of multiple decision points per variable.

[B] The coefficient of quadratic terms denotes the curvature. In this case the negative coefficient indicates that the curve is concave, with dogs in the middle of the age range at highest risk.

\section{Additional File Legends}

File name: Additional file 1

File format: .tiff

Title of data: Variable plots from Elastic Net overweightness/obesity model

Description of data: Variable coefficients averaged across 20 iterations of the overweightness/obesity model

File name: Additional file 2

File format: .tiff

Title of data: Variable plots from Elastic Net obesity model

Description of data: Variable coefficients averaged across 20 iterations of the obesity model

File name: Additional file 3

File format: .tiff

Title of data: Variable plots from XGBoost overweightness/obesity model 
Description of data: Variable importance averaged across 20 iterations of the overweightness/obesity model

File name: Additional file 4

File format: .tiff

Title of data: Variable plots from XGBoost obesity model

Description of data: Variable importance averaged across 20 iterations of the obesity model

File name: Additional file 5

File format: .xls

Title of data: Table 5: Survey Questions

Description of data: Question and answer choices for all survey questions included in the exclusion criteria and final analyses

File name: Additional file 6

File format: .xls

Title of data: Table 6: Imputation Accuracy

Description of data: Mean squared error and proportion falsely classified for each question in the survey

\section{Figures}


A

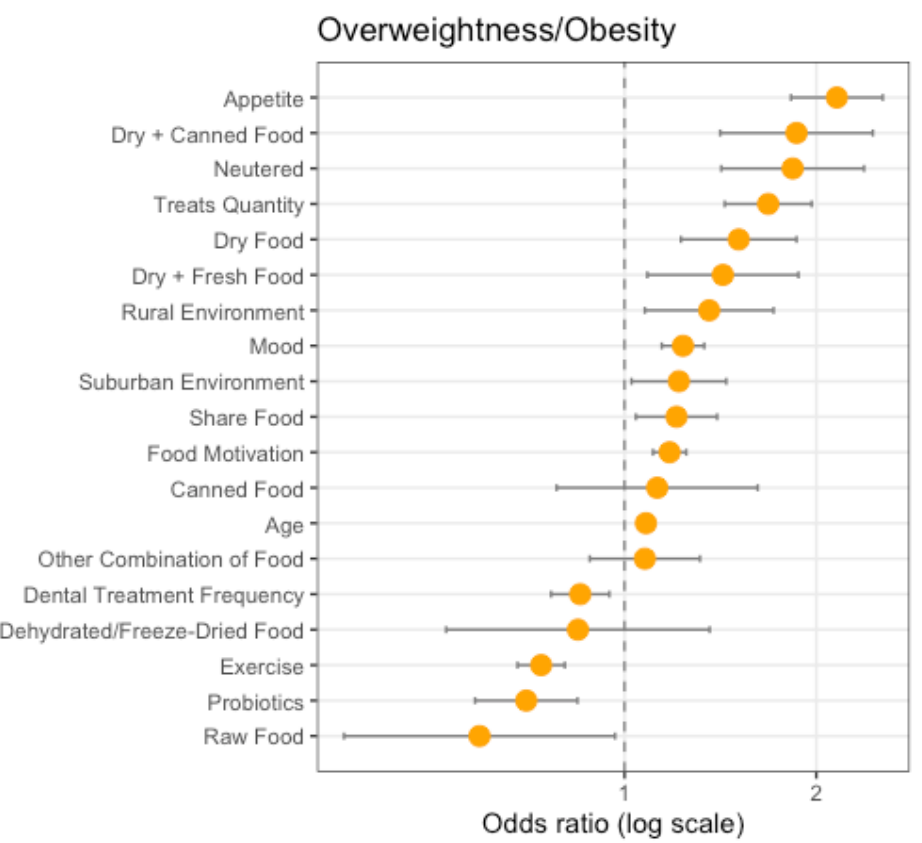

B

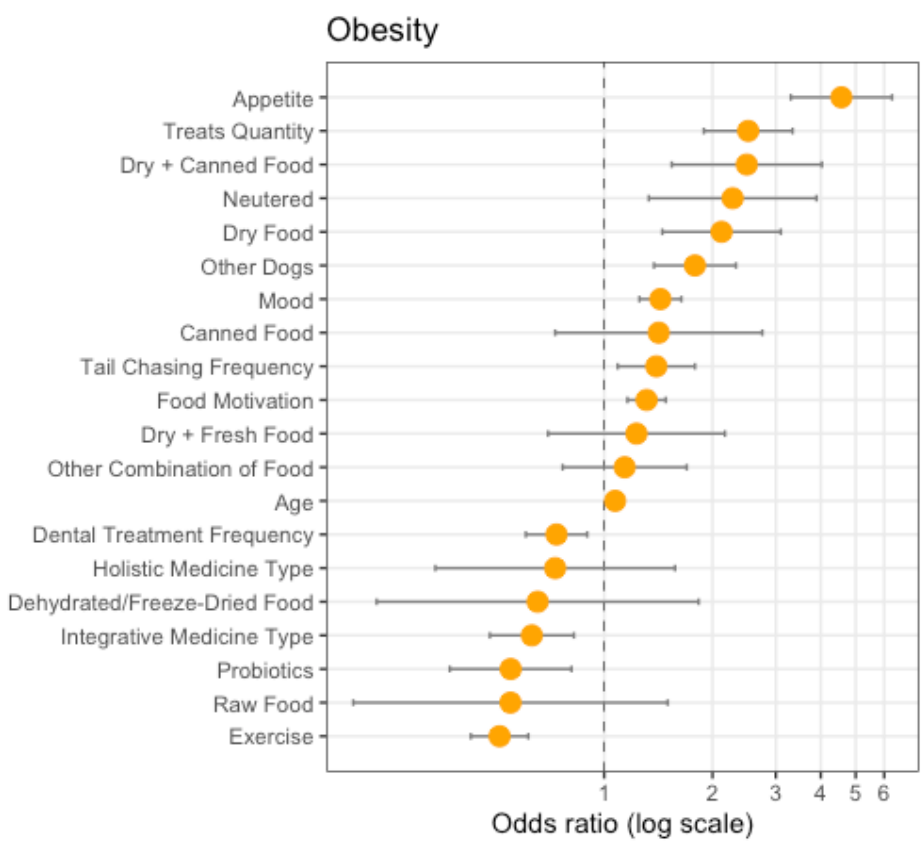

\section{Figure 1}

Variable Log Odds in Final Stepwise Models Legend: Odds ratios for each significant variable in the final model for (A) overweightness and obesity and (B) obesity alone shown. Error bars show the $95 \%$ confidence interval for each risk factor. Diet risk factors are shown relative to a fresh diet, home environment risk factors are shown relative to an urban environment, and medicine type risk factors are shown relative to conventional medicine only.

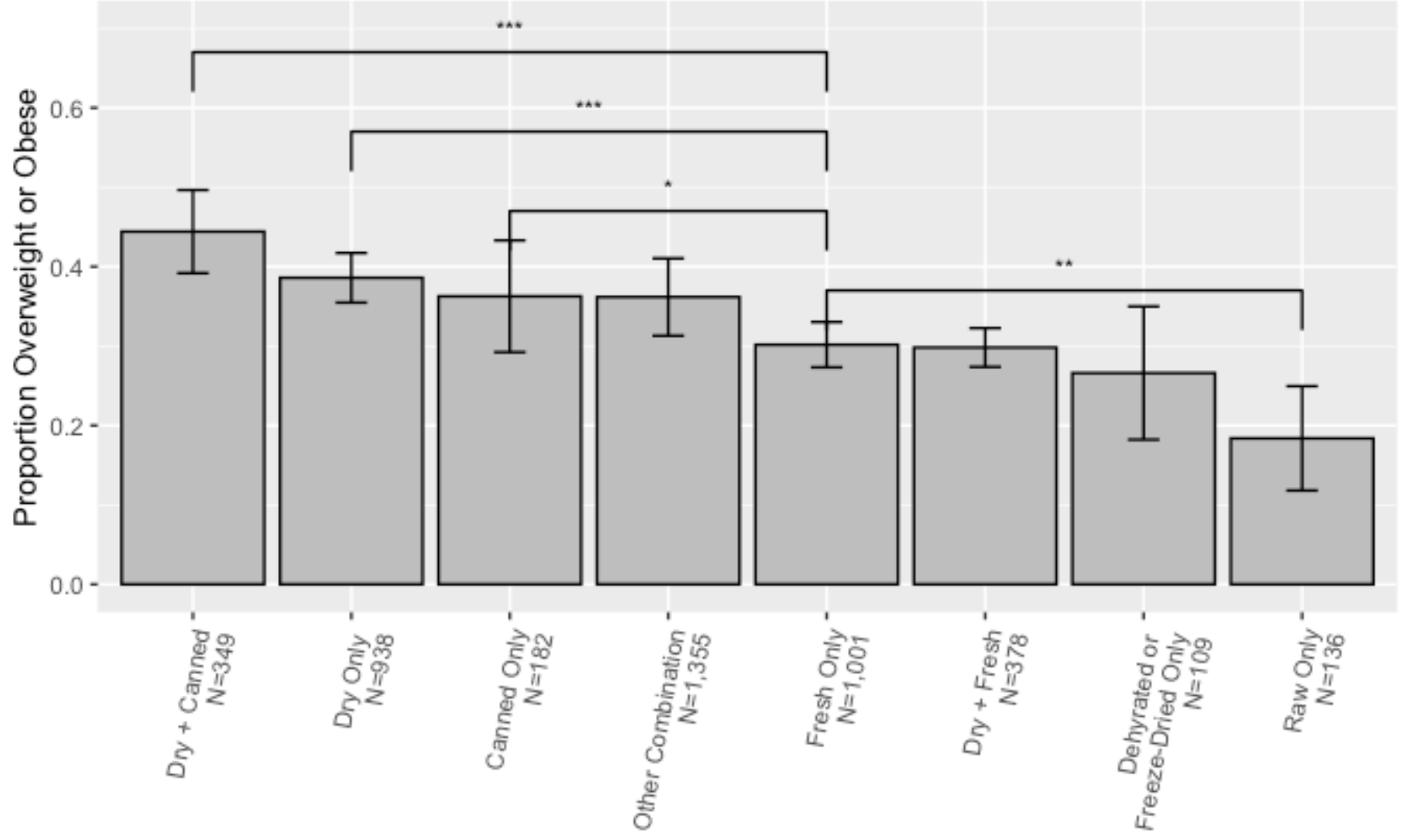

Diet 
Figure 2

Proportion of Dogs Overweight/Obese Relative to a Fresh Food Diet Legend: Error bars show 95\% confidence intervals. ${ }^{*}{ }^{\star *}, \star \star \star$ respectively represent $p<0.05, p<0.01, p<0.001$. "Other" includes any combination of reported dietary elements not represented in the most common dietary configurations, for example having three or more regular dietary elements.

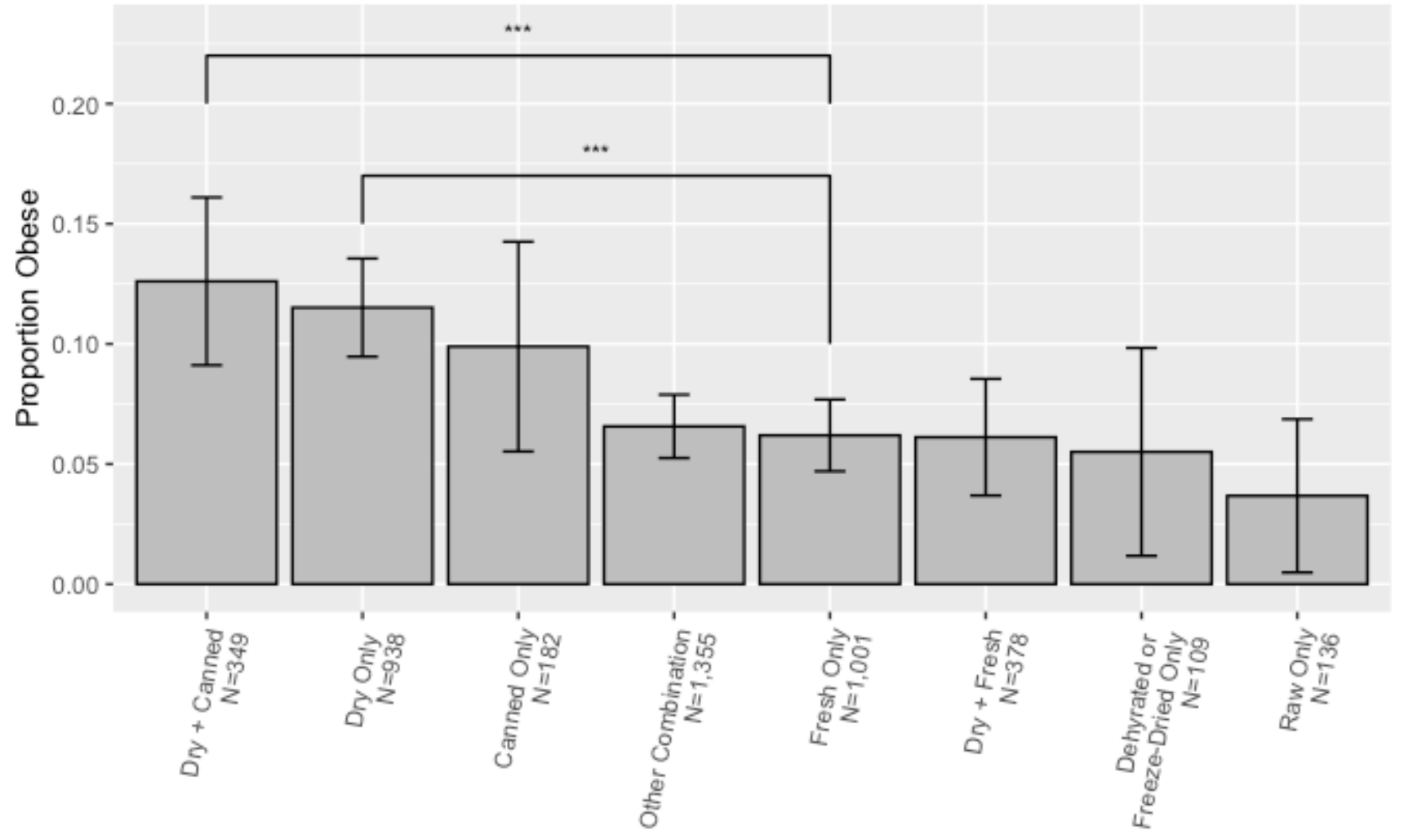

Diet

\section{Figure 3}

Proportion of Dogs Obese Relative to a Fresh Food Diet Legend: Error bars show 95\% confidence intervals. $*{ }^{*} * *, * * *$ respectively represent $p<0.05, p<0.01, p<0.001$. "Other" includes any combination of reported dietary elements not represented in the most common dietary configurations, for example having three or more regular dietary elements. 


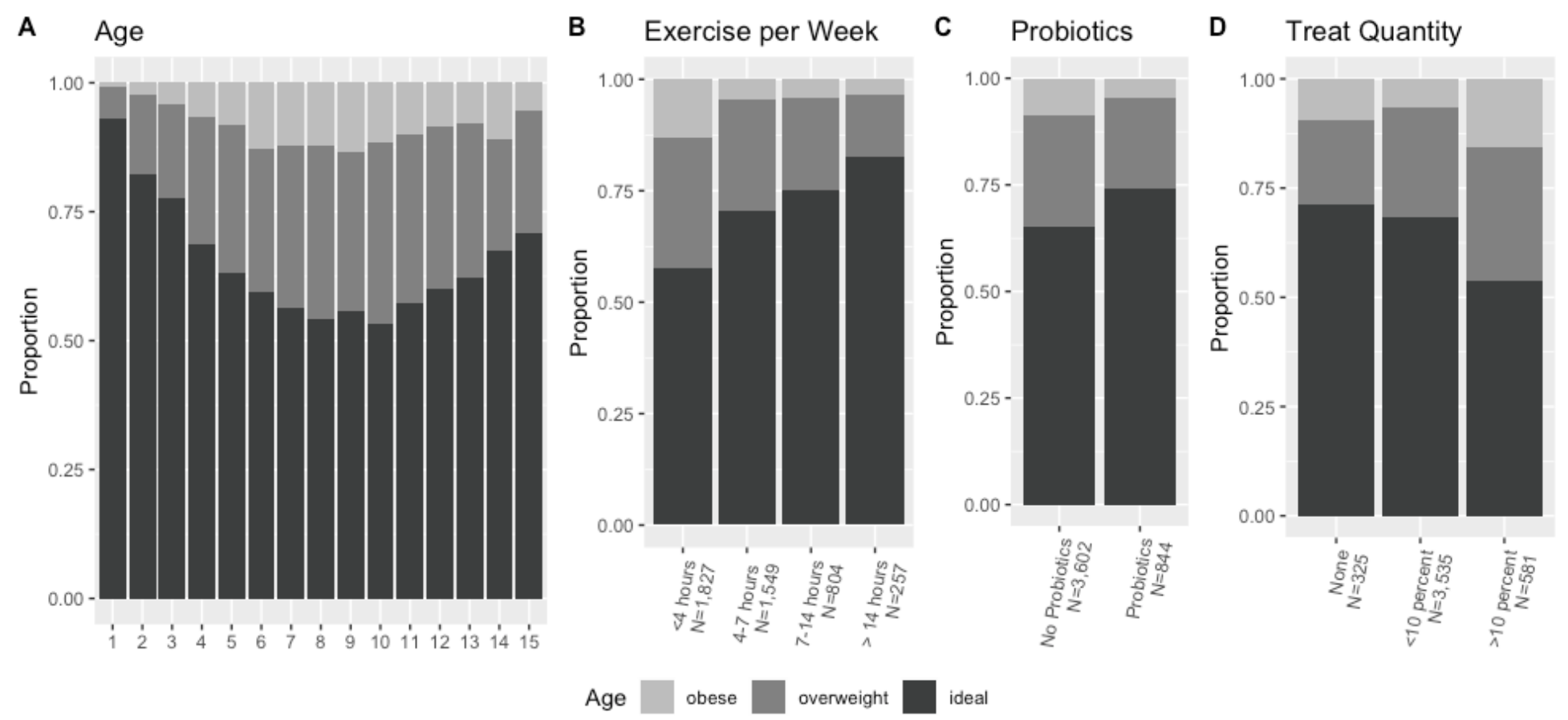

Figure 4

Factors Influencing Body Condition Scores Legend: Proportion of overweight and obese dogs by age (A), exercise per week (B), probiotic consumption (C), and treat quantity (D). 
1. Which body condition illustration or picture best matches Slothrop's current condition? *
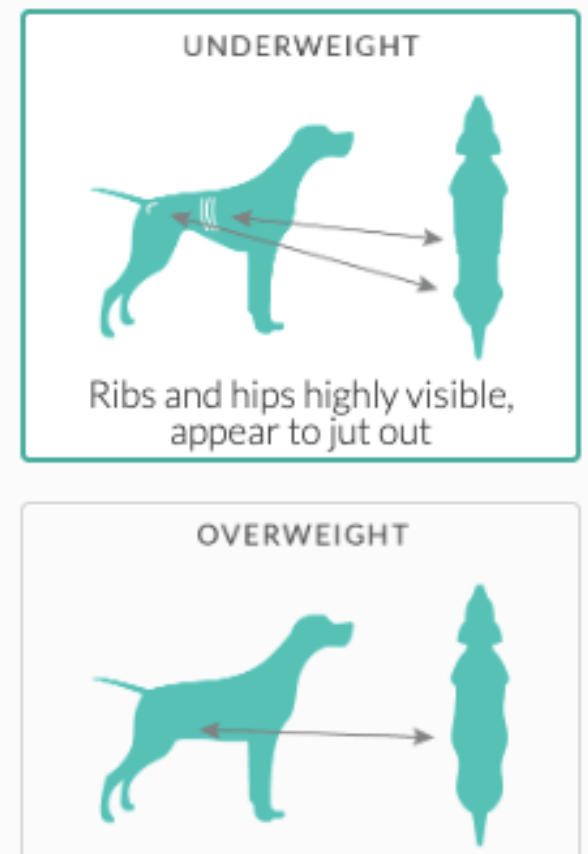

Slight waist visible from top, ribs covered by excess fat

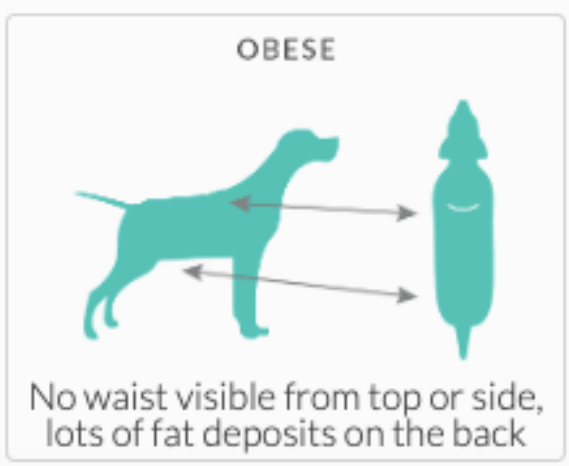

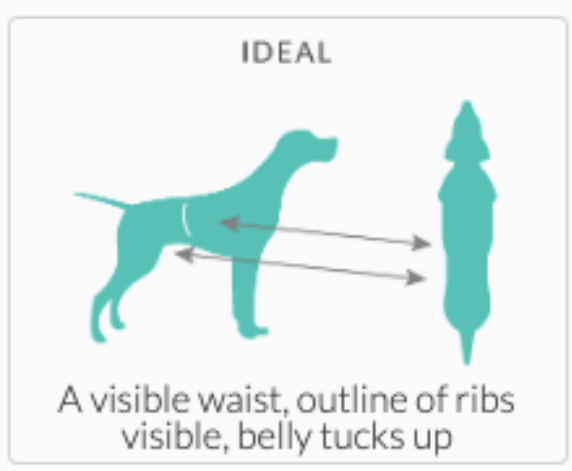
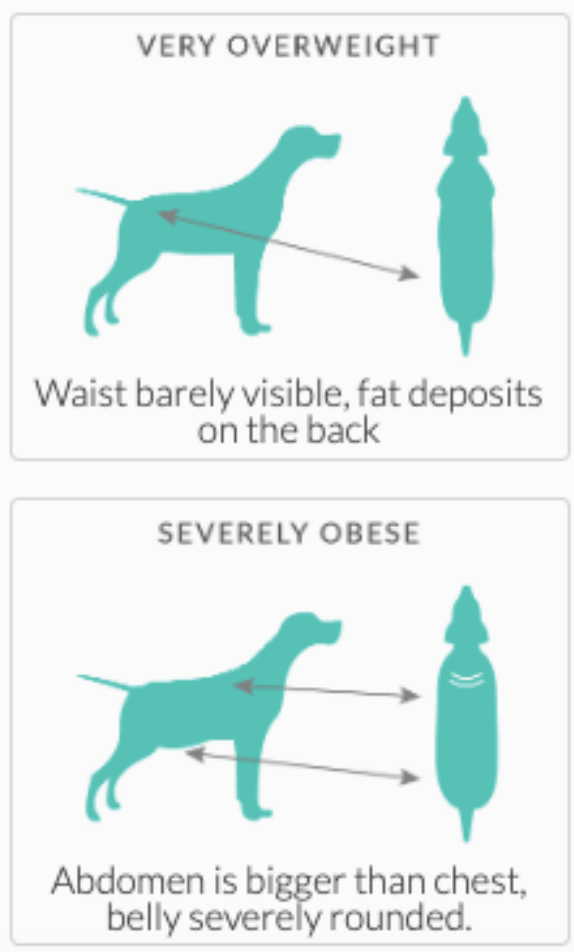

\section{Figure 5}

Body Condition Score Legend: Survey question for body condition shown to respondents.

\section{Supplementary Files}

This is a list of supplementary files associated with this preprint. Click to download.

- AdditionalFile5.xIsx

- AdditionalFile4.tiff

- AdditionalFile2.tiff

- AdditionalFile1.tiff

- AdditionalFile3.tiff 
- AdditionalFile6.xIsx

Page 31/31 